\title{
ИЛЬЯ САМУИЛОВИЧ ГУРВИЧ О ПОЛИТИКЕ ПАТЕРНАЛИЗМА В ОТНОШЕНИИ КОРЕННЫХ НАРОДОВ СЕВЕРА
}

\begin{abstract}
Исследования И.С. Гурвича о политике патернализма в отношении коренньх народов Севера в контексте противоречивых высказываний о ней современных авторов становятся в настоящее время весьма актуальными. Гурвич признавал, что советская политика патернализма в первую очередь обеспечивала приоритет государственных интересов. Но при этом он был убежден в том, что современные ему принципы государственного управления одновременно ориентировались на удовлетворение потребностей коренного населения Севера и на гармоничное соотнесение этих потребностей с интересами централизованной власти. Именно согласованность интересов и потребностей субъекта и объекта управления обеспечивала, по его мнению, эффективность политики патернализма и консолидированную поддержку ее со стороны населения. Гурвич считал провидимую советским государством модернизацию культур коренных народов Севера надежным средством воплощеения в жизнь провозглашенного в стране равноправия всех народов и верил, что достижение этого равноправия востребовано среди коренных жителей Севера. Исследователь был убежден в том, что будущеее не за консервацией традиционных аспектов культуры, но за развитием этнической культурь в контексте неизбежных сочиокультурных трансформаций. Исследования Гурвича доказывают неизбежность и необходимость приобщения коренных жителей Севера к культурным достижениям других народов, которое, не умаляя их этнического самосознания, способствуют социокультурной интеграции в пределах как отдельных регионов, так и всей страны.
\end{abstract}

Ключевые слова: И.С. Гурвич, политика патернализма, культура коренньх народов Севера, этническая специиика культуры коренных народов

Понимание представителем советской науки Ильей Самуиловичем Гурвичем значения политики СССР в отношении коренных народов Севера существенно отличается от сегодняшних взглядов на тот же предмет. Но и современные исследователи оценивают эффективности этой политики по-разному. Одни отмечают положительные ее результаты: формирование института социальной защиты, «оживление основных отраслей северного хозяйства» (Юдин 2013: 5-6), обретение народами Севера ряда преимуществ, позволивших им «получить доступ к здравоохранению,

Булгакова Татьяна Диомидовна - д-р культурологии, профессор, Институт народов Севера Российского государственного педагогического университета им. А.И. Герцена (195426 Санкт-Петербург, ул. Ленская, 8-1-10). Эл. почта: tbulgakova@gmail.com Bulgakova, Tatyana D. - Dr. of Culturology, Prof., Institute of Peoples of the North, Herzen State Pedagogical University of Russia (Saint-Petersburg, Russia). E-mail: tbulgakova@gmail.com 
образованию и социальному обеспечению, сохранить свои языки и культуру, традиционную экономику наравне с государственной, в конце концов, многим из них избежать биологического исчезновения» (Гоголев 2014: 49). Другие авторы считают концептуально ошибочной саму необходимость патерналистских форм поддержки со стороны государства, поскольку это, по их мне-

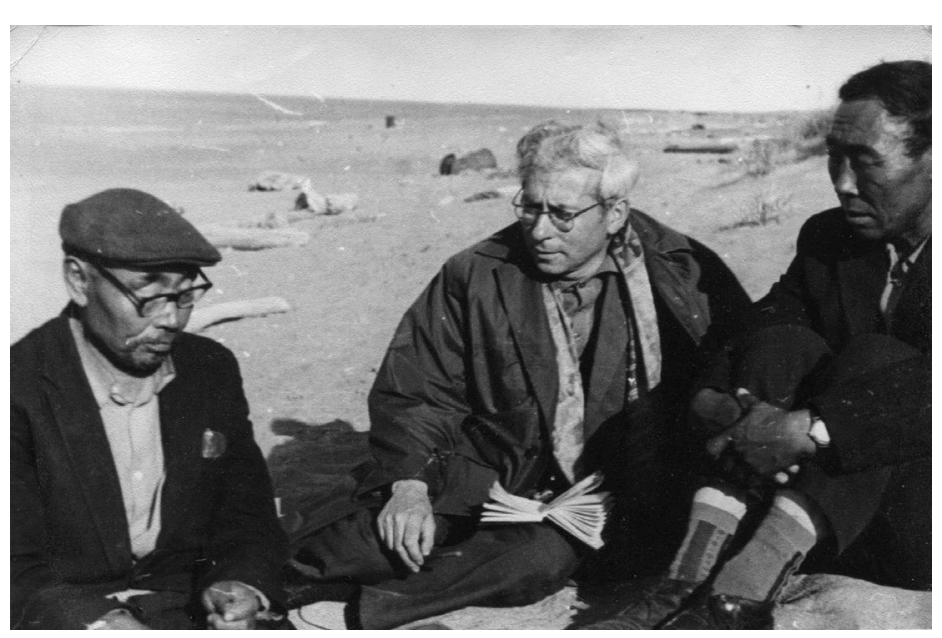

Рис. 1. И.С. Гурвич беседует с информантами (фото из архива семьи Гурвич, 2020). нию, развило у представителей коренных народов Севера «иждивенческие настроения и чувства зависимости от государства» (Поворознюк 2005: 209). Когда в ходе социально-экономических реформ 1990-х гг. «основные советские институты были разрушены», именно политику советского периода в отношении коренных малочисленных народов Севера, основанную на принципах государственного патернализма, стали винить в том, что она стала «одной из причин чрезвычайно низкого уровня жизни коренных народов» (Виноградова 2010: 127). По-разному оценивается современными учеными эффективность патерналистского подхода. Одни из них указывают его на концептуальную ошибочность и полагают, что негативные явления постсоветского периода являются следствием политики советского патернализма (Пика 1996). Другие исследователи напротив считают эти негативные явления результатом отказа от политики патернализма и деструктивных процессов периода перестройки (Юдин 2012: 41). Они выступают за то, чтобы «восстановить политику государственного регулирования через прямую поддержку бедных групп аборигенного населения Севера» (Донской и дp. 2003: 62), поскольку именно «отказ от государственного патернализма, декларирование протекционистских и партнерских отношений с коренными малочисленными народами Севера во многом подорвали их социально-экономическое положение» (Там же). В контексте такого разнообразия мнений целесообразным было бы проанализировать ту аргументацию, которую использовал советский исследователь И.С. Гурвич, интерпретировавший политику патернализма как эффективное средство преодоления «многовековой отсталости» коренных народов Севера, считавший серьезным достижением совершавшуюся «на социалистической основе» перестройку хозяйства коренных народов, их традиционного быта и культуры.

\section{Интерпретация Гурвичем потребностей объекта управления в контексте политики патернализма}

Значительные расхождения в интерпретации сущности политики патернализма могут быть обусловлены воздействием на науку различных политических пред- 
почтений и идеологизированных установок исследователей. Риторика же Гурвича определялась идеологией советского периода, приятием советской модели национального развития. По его мнению, насущной потребностью отдельных этнических групп на Севере в раннесоветский период было преодоление «отсталости» и модернизация культуры. Он ратовал за обретение коренными народами письменности, за обеспечение всеобщей доступности школьного образования, предполагающей возможность обучения на родном языке, развитие периодической печати на языках народов Севера, за рост материального благосостояния коренного населения, улучшение его быта. «Укрепление материально-технической базы промыслового хозяйства, - писал Гурвич, - позволило ввести гарантийную оплату труда в колхозах, повысить заработки населения, как в колхозах, так и в совхозах. Денежные доходы в промысловых хозяйствах в северных национальных округах за 1958-1966 гг. выросли в 2,5 раза. Это оказало огромное влияние на быт коренного населения, повышение его культурного уровня» (Гурвич 1971: 41-42). Высказывания Гурвича были созвучны тому, что говорили о модернизации и другие исследователи советского времени, писавшие о необходимости ликвидации «исторически сложившегося фактического неравенства» народов России и «разных уровней общественно-экономического и культурного развития», указывавшие на важность «быстрого подъема экономики и культуры отсталых народностей до уровня передовых народов» (Вдовин 1967: 79). Гурвич вдохновенно сообщал в своих трудах о «широким фронтом развернувшемся школьном строительстве на Севере», позволившем в некоторых местах даже «осуществить всеобщее начальное образование» (Гурвич, Таксами 1985: 56). Он отмечал, что в советское время стали исследоваться языки народов Севера, создаваться письменность для тех языков, которые еще ее не имели, языки стали изучаться в начальных классах школ в северных регионах (Гурвич, Таксами 1985: 59), и что именно создание письменности языков народов Севера «сыграло важную роль в ликвидации неграмотности, в становлении начального школьного образования» (Гурвич, Таксами 1985: 55). Такую модернизацию он считал надежным средством воплощения в жизнь провозглашенного в стране равноправия всех народов, будучи убежденным в том, что достижение именно этого равноправия прежде всего востребовано среди коренного населения Севера.

\section{Гурвич о приоритете государственных интересов}

Говоря о преимуществах, которые получало коренное население в результате политики патернализма, Гурвич одновременно признавал и то, что политика эта обеспечивала приоритет государственных интересов. Модернизировать быт коренных народов Севера нужно было, по Гурвичу, в первую очередь для того, чтобы приобщить их «к сознательному строительству новой жизни» (Гурвич, Таксами 1985: 55), чтобы способствовать решению первоочередной задачи того времени: интеграции и консолидации страны как в языковом, так и в культурном отношении. «Языковая обособленность», «диалектальная разобщенность» вызывала неодобрение Гурвича не потому, что казалась ему плохой сама по себе, а потому, что являлась «тормозом на пути социальных преобразований» (Там же). Разобщенность способствовала, по Гурвичу, «замкнутости этнических и этнографических групп», тогда как требовалось «преодоление былой культурной замкнутости этнических, диалектных и территориальных групп в составе 
отдельных народностей» и в связи с этим укрепление их этнического единства (Гурвич, Таксами 1985: 63). Признавая «искренность добрых намерений» «группы наивных энтузиастов», осуществлявших политику интеграции и стремившихся помочь, например, эвенкам (тунгусам) С.М. Широкогоров, писал, что помощь осуществлялась в первую очередь именно потому, что «тунгусы были нужны определенной политической партии по определенным политическим причинам» (Shirokogoroff 1991). Государственная политика тотальной интеграции и ассимиляции описывалась Гурвичем как стремление к тому, чтобы «общенародное самосознание получило преобладание над локальными формами» (Гурвич 1972: 27) и оценивалась положительно не в последнюю очередь именно потому, что такая политика отвечала интересам властных структур, способствовала усилению централизованной власти.

\section{Гурвич об этнической специфике культуры коренных народов в контексте интеграционной политики}

Противоречивым кажется отношение Гурвича к неизбежному следствию модернизации советского периода, заключавшемуся в снижении уровня культурного разнообразия и в утрате интереса коренных жителей к родным языкам. С одной стороны, он признавал, что замена «старых форм материальной культуры современными» отрицательно воздействует на этническую специфику отдельных явлений культуры каждого северного народа (Гурвич 1967: 75). Так, «с ростом культуры, подъемом материального благосостояния» якутов, например, «перестали удовлетворять их традиционные юрты-балаганы», что «после коллективизации эти “особенности” культуры якутов, разумеется, исчезли. Широкое распространение у них получило срубное жилище и городские формы одежды» (Гурвич 1967: 74-75). Эти его рассуждения созвучны современной критике политики патернализма, указывающей на необратимые негативные последствия таких «изменений, как утрата навыков ведения традиционного хозяйства», сокращение сферы использования языков коренных народов Севера, «трансформация духовных традиций и народных промыслов» (Поворознюк 2005: 119).

С другой стороны, Гурвич не считал необходимой консервацию с помощью языков традиционных аспектов культуры, он верил в неизбежность социокультурных трансформаций, которым должна быть подвержена культура народов Севера так же, как и любая другая культура. Поэтому он позитивно оценивал «приобретение языками народностей Севера и Дальнего Востока новых социальных функций в области просвещения, книгоиздательства, периодической печати (Гурвич, Таксами 1985: 63). Этот взгляд соответствовал задачам советского периода, когда государственное управление руководствовалось необходимостью сохранения не только традиционных функций языков народов Севера, но и формированием новых их социальных ролей, складывавшихся, прежде всего, в области просвещения, книгоиздательства и периодической печати (Вдовин 1967: 79). С удовлетворением Гурвич писал о том, что «даже на языках народностей, насчитывающих в своем составе всего несколько десятков тысяч человек, издаются учебники, художественная литература и газеты... разработаны алфавиты для таких языков, как ительменский, удэгейский, юкагирский, хотя численность их носителей не превышает нескольких сот человек» (Гурвич 1982: 18).

Между тем то, что кажется в высказываниях Гурвича противоречивым, объясняется его стремлением соотносить интересы субъекта и объекта управления в сфере 
патерналистской политики Советского государства. Гурвич подчеркивал, что «в целом языковая жизнь в стране характеризуется не вытеснением родных языков русским, не языковой ассимиляцией, а параллельно идущим развитием родных языков и распространением двуязычия» (Гурвич 1982: 19). Одновременно он постоянно говорил о необходимости «сохранения и развития родных языков и национальной культуры», а также о необходимости широко использовать родные языки в сфере «сознательного строительства новой жизни», поскольку это «оказывает большое влияние на этническую идентификацию их носителей» (Гурвич, Таксами 1985: 63).

Признавая, что с «внедрением в быт техники, новых форм жилища, одежды, обуви, новых видов пищи материальная культура во многом утратила свои этнические признаки» (Гурвич 1982: 16), исследователь отмечал, что утрата этнической специфики совершается лишь в отдельных сферах культуры и не касается всей культуры как целого. Он оптимистично оценивал возможности сохранения национальной специфики в процессе модернизации. Социализм, по мнению Гурвича, «не только не ведет к утрате народами своего неповторимого лица, особенностей культуры, традиций, а поднимает это своеобразие на новую высоту и делает его достоянием многих народов» (Гурвич 1982: 27). Что касается этнической специфики культуры народов СССР, она, по мнению автора, резко перемещается «из сферы традиционной материальной культуры в сферу духовной, главным образом профессиональной, культуры» (Гурвич 1982: 16), в результате чего «разграничительная линия между национальными культурами» стала обнаруживать себя «не в различии форм жилища, одежды, пищи, а более глубоко - прежде всего в области языка, литературы, искусства» (Гурвич 1967: 76).

\section{Гурвич о соотнесенности интересов субъекта и объекта управления}

Понимание процессов изменения и сохранения этнического самосознания и необходимости поддержания специфики культурного наследия народов Севера обусловливалось у Гурвича таким пониманием сущности политики патернализма, которое основывалось на согласованности интересов субъекта и объекта управления (в той мере, конечно, в какой государственным структурам удавалось разобраться в сущности интересов коренного населения). Упрощая ситуацию, можно было бы предположить, что задача управления заключается в модернизации культуры и в размывании этнической идентичности, а интересы управляемых направлены на консервацию традиций и сохранение этнического самосознания. Но представление Гурвича о сущности патерналистской политики сложнее. Модернизация, согласно его высказываниям, призвана не ослаблять, но, наоборот, усиливать этническое самосознание. Исследователь выступал вовсе не за русификацию. Напротив, он был сторонником поддержки «стойкого бытования и развития языков народов СССР» и «неуклонного подъема национальных культур» (Гурвич 1982: 18).

При этом понятию «национальная культура» в его работах далеко не всегда соответствует понятие «культура того или иного конкретного этноса». Гурвич был сторонником сложения «зональных культурных общностей», характеризующихся, как он это объяснял, распространением среди народов, входящих в одну зону, «отдельных приспособленных к самой природно-географической среде и выдержавших испытание временем некоторых форм одежды, обуви, жилища и пищевого режима, производственных навыков». В таких зонах, по его мнению, «часто распространя- 
ются также сходные традиции в области фольклора, литературы и изобразительного искусства». Крайний Север должен стать, как считал исследователь, местом «широкого обмена культурным достоянием между соседними народами» (Гурвич 1967: 76).

Ярким примером такого, с одной стороны, сохранения, a с другой стороны, преодоления традиций является его отношение к проблеме диалектного и культурного раз-

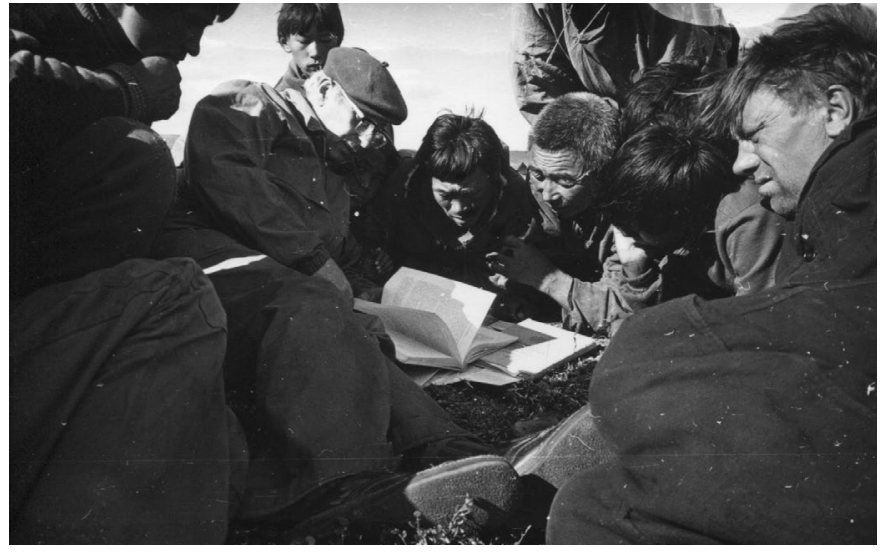

Рис. 2. Работа в "поле"

(фото из архива семьи Гурвич, 2020).

нообразия, сложившегося на Севере в условиях дисперсности расселения коренных народов и относительной изоляции ряда районов от культурных центров. Ученый принимал как должное то обстоятельство, что при создании и внедрении письменности ряда коренных народов Севера, языки которых отличались наличием множества диалектов, требовалось в первую очередь формирование наддиалектного стандарта. С самого начала выявление такого стандарта столкнулось со множеством трудностей, одной из которых было то обстоятельство, что «письменность, созданная на основе опорных диалектов, в ряде случаев оказалась недоступной носителям других диалектов и не получила у них распространения» (Гурвич, Таксами 1985: 56-57). Это случилось оттого, что, как указывал С.М. Широкогоров, в тот краткий период времени, который был отведен для решения государственной задачи по созданию письменности коренных народов «знания о диалектах были слишком недостаточными для того, чтобы строить какие-либо планы их развития» (Shirokogoroff 1991). Кроме того, негативные последствия чрезмерного диктата власти проявились в том, что создание «литературных языков» «не было обусловлено культурными потребностями» коренных народов и не осуществлялось ими самими (Shirokogoroff 1991).

Но Гурвич в отличие от Широкогорова оценивал эту деятельность исключительно в позитивном ключе. По его мнению, «она проводилась под руководством опытных лингвистов молодыми энтузиастами этнографами, языковедами, фольклористами, направлявшимися на Север по призыву Комитета содействия народностям северных окраин в качестве учителей, фельдшеров, руководителей культбаз, красных яранг и т. д. В 1926 г. эту работу возглавил Северный факультет Ленинградского восточного института, а позднее - Научно-исследовательская ассоциация Института народов Севера» (Гурвич, Таксами 1985: 56). Хотя следует признать и следующий факт. Несмотря на то, что «в создании письменности на языках народностей Севера, подготовке учебников и словарей участвовали и представители этих народностей, учителя, студенты, слушатели окружных курсов по подготовке колхозы кадров (нанайцы, коряки, эскимосы, чукчи)» (Там же), это не опровергает того обстоятельства, что роль представителей коренных народов была все же вторична, и что в целом инициатива создания письменности определялась патерналистской установкой. 


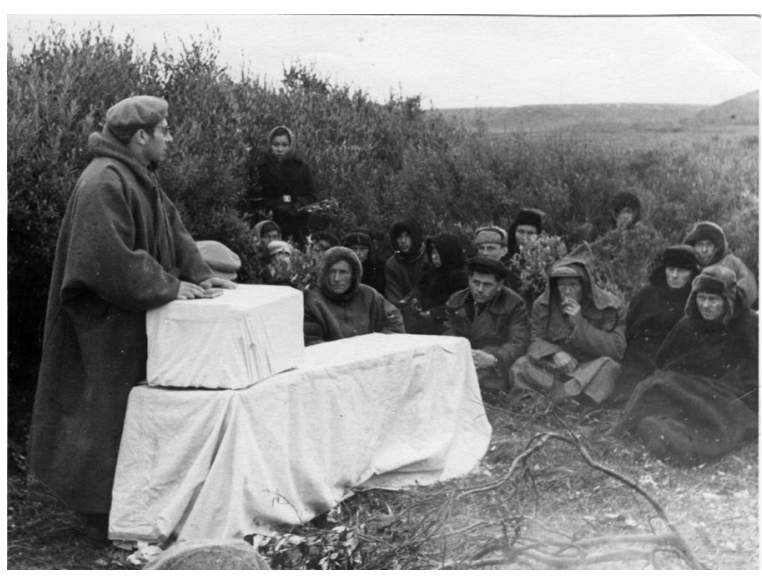

Рис. 3. Лекциия "в поле”

(фото из архива семьи Гурвич, 2020).

По мнению Гурвича, одним из основных достижений политики патернализма стал «расцвет национальных культур». Сопутствующим этому расцвету достижением и результатом такого расцвета он считал «внутреннее сплочение» наций и народностей, количество которых уменьшилось за счет укрупнения разрозненных ранее групп, многие из которых прежде не обладали сознанием своей этнической идентичности. Гурвич приветствовал то обстоятельство, что «в условиях широкого распространения среднего и высшего образования национальное самосознание становится все более четким и мотивированным» (Гурвич 1982: 24), в результате чего «из очень зыбкого, по сути легендарного представления понятие "национальное происхождение” превратилось у многих народов в весьма важный элемент национального самосознания» (Гурвич 1982: 24).

Модернизация и реконструкция культуры коренных народов Севера не только не размывала этническую идентичность, но напротив, способствовала формированию и укреплению этнического самосознания «укрупненных» в результате модернизации этнических групп. Таким образом она соответствовала, с одной стороны, интересам коренного населения, понятым (интерпретированным) властью как заинтересованность в этнической консолидации и укреплении этнической идентичности, а с другой стороны, способствовала интеграции общества в соответствии с государственными интересами того времени.

Как на достижение политики патернализма указывал Гурвич на то обстоятельство, что «список национальностей между переписями 1926 и 1939 гг. сократился, объясняя это консолидационными процессами. Ряд групп, осознававших себя самостоятельными этносами, в течение 1920-1930-х годов слились с более крупными народностями» (Гурвич 1982: 16). Как об успехе, способствовавшем преодолению дезинтеграции, Гурвич писал о том, что «социалистическое переустройство хозяйства и быта коряков» привело «к сближению двух основных групп этой народности - кочевых оленных и оседлых морских зверобоев, распадавшихся, в свою очередь, на ряд локальных подразделений, не всегда осознававших свое этническое единство» (Гурвич 1972: 26-27).

В настоящее время становится понятным, что в силу недостаточной компетентности управления и изоляции субъекта и объекта управления успех всех этих мероприятий был меньшим, чем это виделось Гурвичу. Так, границы национальных округов определялись без согласования с коренным населением и в спешке. «Главным критерием была значительная доля представителей того или иного северного народа среди проживающих на территории» (Виноградова 2010: 131). Особенно болезненной оказалась «проблема перевода на оседлость оленеводов тундры, т. е. изжития производственного кочевания» (Вдовин 1967: 86). При этом считалось, что мероприятия по ликвидации бытового кочевания были оправданы, поскольку проводились с целью 
«улучшения условий труда и быта занятого в оленеводстве населения» (Там же). Гурвич также позитивно оценивал «создание крупных коллективных хозяйств, переход значительной части населения на оседлую жизнь», «изживание былой диалектальной пестроты» и «диалектальных различий», «браки между представителями разных корякских групп», потому что все это, на его взгляд, способствовало упрочению единства этнических общностей и вело к превалированию общенародного самосознания над локальными формами идентичности (Гурвич 1982: 27). Таким образом, Гурвич был убежден в том, что современный ему принцип государственного управления не столько обеспечивал вмешательство власти в культуру коренных жителей, сколько находил такие аспекты управления, в которых гармонично соотносились потребности централизованной власти с интересами коренного населения Севера.

\section{Заключение. Современный патернализм в осуществлении антиинтеграционной политики}

Различия в отношении исследователей к эффективности политики патернализма обусловлены разным их толкованием интересов объекта управления. Если в советское время, как видно из трудов Гурвича, считалось, что модернизация для коренных жителей Севера - это благо, то в настоящее время принято считать, что благом для них является возвращение к утраченным традициям. В советское время положительным считалось достижение интеграции этнических групп на региональном или на общегосударственном уровне. Напротив, в постсоветский период общим местом стало представление о том, что только усиление существующих этнических и социальных границ, только дифференциация культурных особенностей этнических групп является той целью, к которой стремятся представители коренного населения. Несмотря на расхождения между декларируемыми и действительными нуждами объекта управления, сам принцип патернализма, то есть, стремление власти понять и реализовать интересы объекта управления остается прежним, «политика патернализма по отношению к коренным народам» сохраняется и в настоящее время, наполняясь лишь иным содержанием, содействуя поддержанию этнокультурных различий и способствуя «усилению существующих этнических и социальных границ» (Куропятник 2006: 281). В русле протекционизма осуществляется современное «возрождение» культурных традиций коренных народов. Апелляция к архаике оказывается искусственной, а актуализация этнонационального фактора бесперспективной в случае, если местные этнические традиции разрушены настолько, что «возрождение их» в действительности оказывается чуждой этим традициям новацией (Булгакова 2015).

Обращение к трудам Гурвича помогает осознать неоднозначность феномена патернализма, способного по-разному проявляться в меняющемся социокультурном контексте. Проводивший полевые исследования Гурвич из первых рук знал о нуждах коренного населения, об его отношении к преобразованиям советского периода, его поддержке определенных процессов модернизации. Это давало ему возможность избегать крайностей в оценке эффективности и целесообразности политики патернализма. Исследовательский пафос Гурвича вдохновлялся верой в необходимость такого приобщения коренного населения Севера к культурным достижениям других народов, которое не умаляя их этническое самосознание, должно было способствовать их социокультурной интеграции в пределах как региона, так и всей страны. 


\section{Научная литература}

Булгакова Т.Д. Становление этнической идентичности в Сибири: роль традиций и современных институтов // Humanities and Social Sciences. Журнал Сибирского федерального университета. Journal of Siberian Federal University. Красноярск, 2015. № 8 (Supplement). C. 227-236.

Вдовин И.С. Малые народности Севера на социалистическом пути развития за 50 лет Советской власти // Советская этнография, 1967. № 5. С. 78-91.

Виноградова С.Н. Формирование государственной политики в отношении коренных малочисленных народов Севера, Сибири и Дальнего Востока: ретроспективный анализ // Труды Кольского научного центра РАН, 2010. С. 127-139.

Гоголев П.В. Конституционно-правовые основы патернализма и партнерства в отношении коренных малочисленных народов Севера, Сибири и Дальнего Востока России. Дисс. ... докт. юр. наук. МГУ им. М.В. Ломоносова. Москва, 2014. 434 с.

Гурвич И.С. Некоторые проблемы этнического развития народов СССР // Советская этнография. 1967. № 5. С. 62-77.

Гурвич И.С. Особенности современного этапа этнокультурного развития народов Советского Союза // Советская этнография. 1982. № 6. С. 15-27.

Гурвич И.С. Принципы ленинской национальной политики и применение их на Крайнем Севере // Осуществление ленинской национальной политики у народов Крайнего Севера. М.: Наука, 1971. С. 9-49.

Гурвич И.С. Современные направления этнических процессов в СССР // Советская этнография. 1972. № 4. С. 16-33.

Гурвич И.С., Таксами Ч.М. Социальные функции языков народностей Севера и Дальнего Востока СССР в советский период // Советская этнография. 1985. № 2. С. 54-63.

Донской Ф.С., Роббек В.А., Шейнин Ю.А. Интеграция коренных малочисленных народов Сибирского Севера и Дальнего Востока в общероссийскую культуру. Якутск: Издательства CO PAH, 2003. $424 \mathrm{c}$.

Куропятник М.С. Коренные народы в процессе социокультурных изменений. Санкт-Петербург: СПб гос. университет: Дисс. д-ра социол. наук. 2006. 360 с.

Пика А.И. Неотрадиционализм на Российском Севере: идти в будущее, не забывая прошлого // Социологические исследования. 1996. № 11. С. 47-53.

Поворознюк O.A. Эвенки севера Читинской области: социальные, экономические и культурные трансформации на рубеже XX-XXI веков. Дисс. на соиск. учен. степ. кандидата исторических наук. Москва: Институт этнологии и антропологии им. Н.Н. Миклухо-Маклая РАН. 2005. 318 c.

Юдин В.И. Государственная политика в отношении коренных малочисленных народов Севера: историко-политологический анализ // Власть и управление на Востоке России. 2013. № 4 (65). C. 1-10.

Юдин В.И. Государственная политика в отношении коренных малочисленных народов Севера: социально-политический анализ // Власть. 2012. № 2. С. 40-44.

Shirokogoroff S.M. Tungus Literary Language // Asian Ethnology, 1991. Vol. 50/1. http://www. shirokogorov.ru/s-m shirokogorov/publications/tungus_literary_language.

\section{References}

Bulgakova, T.D. 2015. Stanovlenie etnicheskoi identichnosti v Sibiri: rol' traditsii i sovremennykh institutov [Formation of ethnic identity in Siberia: the role of traditions and modern institutions]. Humanities and Social Sciences. Zhurnal Sibirskogo federal'nogo universiteta 8 (Supplement): 227-236. Krasnoiarsk. 
Donskoi, F.S., V.A. Robbek, and Iu.A. Sheinin. 2003. Integratsiia korennykh malochislennykh narodov Sibirskogo Severa i Dal'nego Vostoka v obshcherossiiskuiu kul'turu [Integration of small indigenous peoples of the Siberian North and Far East into Russian culture]. Iakutsk: Izdatel'stva SO RAN.

Gogolev, P.V. 2014. Konstitutsionno-pravovye osnovy paternalizma i partnerstva v otnoshenii korennykh malochislennykh narodov Severa, Sibiri i Dal'nego Vostoka. Rossii. [Constitutional and legal foundations of paternalism and partnership in relation to the indigenous peoples of the North, Siberia and the Russian Far East]. Dis. na soisk. uchen. step. doktora iuridicheskikh nauk. Moscow.

Gurvich, I.S. 1967. Nekotorye problemy etnicheskogo razvitiia narodov SSSR [Some problems of ethnic development of the peoples of the USSR] Sovetskaia etnografiia 5: 62-77.

Gurvich, I.S. 1971. Printsipy leninskoi natsional'noi politiki i primenenie ikh na Krainem Severe [Principles of Lenin's national policy and their application in the Far North] In Osushchestvlenie leninskoi natsional'noi politiki u narodov Krainego Severa [Implementation of Lenin's national policy among the peoples of the Far North], 9-49. Moscow: Nauka.

Gurvich, I.S. 1972. Sovremennye napravleniia etnicheskikh protsessov v USSR [Modern trends of ethnic processes in the USSR]. Sovetskaia etnografiia 4: 16-33.

Gurvich, I.S. 1982. Osobennosti sovremennogo etapa etnokul'turnogo razvitiia narodov Sovetskogo Soiuza [Features of the modern stage of ethnocultural development of the peoples of the Soviet Union]. Sovetskaia etnografiia 6:15-27.

Gurvich, I.S. and Ch.M. Taksami. 1985. Sotsial'nye funktsii iazykov narodnostei Severa i Dal'nego Vostoka SSSR v sovetskii period [Social functions of the languages of the peoples of the North and Far East of the USSR in the Soviet period]. Sovetskaia etnografia 2: 54-63.

Iudin, V.I. 2012. Gosudarstvennaia politika v otnoshenii korennykh malochislennykh narodov Severa: sotsial'no-politicheskii analiz [State policy towards the small indigenous peoples of the North: socio-political analysis]. Vlast' 2: 40-44.

Iudin, V.I. 2013. Gosudarstvennaia politika v otnoshenii korennykh malochislennykh narodov Severa: istoriko-politologicheskii analiz [State policy towards the small indigenous peoples of the North: historical and political analysis]. Vlast'i upravlenie na Vostoke Rossii 4 (65):1-10.

Kuropiatnik. M.S. 2006. Korennye narody v protsesse sotsiokul'turnykh izmenenii [Indigenous peoples in the process of sociocultural change]. Sankt-Peterburg: SPb gos. universitet: Diss. d-ra sotsiol. nauk.

Pika, A.I. 1996. Neotraditsionalizm na Rossiiskom Severe: idti v budushchee, ne zabyvaia proshlogo . [Neotraditionalism in the Russian North: to go to the future without forgetting the past]. Sotsiologicheskie issledovaniia 11: 47-53.

Povorozniuk, O.A. 2005. Evenki severa Chitinskoi oblasti: sotsial'nye, ekonomicheskie i kul'turnye transformatsii na rubezhe $X X-X X I$ vekov [Evenki of the North of the Chita region: social, economic and cultural transformations at the turn of the XX-XXI centuries]. PhD diss. Moscow: Institut etnologii i antropologii im. N.N. Miklukho-Maklaia RAS.

Shirokogoroff, S.M. 1991. Tungus Literary Language. Asian Ethnology, 50/1. http://www.shirokogorov.ru/s-m-shirokogorov/publications/tungus_literary_language/01.

Vdovin, I.S. 1967. Malye narodnosti Severa na sotsialisticheskom puti razvitiia za 50 let Sovetskoi vlasti [Small peoples of the North on the socialist path of development for 50 years of Soviet power]. Sovetskaia etnografiia 5: 78-91.

Vinogradova, S.N. 2010. Formirovanie gosudarstvennoi politiki v otnoshenii korennykh malochislennykh narodov Severa, Sibiri i Dal'nego Vostoka: retrospektivnyi analiz [Formation of state policy in relation to small indigenous peoples of the North, Siberia and the Far East: a retrospective analysis]. Trudy Kol'skogo nauchnogo tsentra RAN PAH [Proceedings of the Kola Research Center of the Russian Academy of Sciences], 127-139. 
Bulgakova, Tatyana D.

\section{Ilya Samuilovich Gurvich on the policy of paternalism in relation to the indigenous peoples of the North}

I.S. Gurvich's research on the policy of paternalism in relation to the indigenous peoples of the North is now becoming relevant in the context of the contemporary discussion. Gurvich acknowledged that the Soviet policy of paternalism in the first place gave priority to the public interest. Nonetheless, at the same time, he was convinced that the contemporary principles of public administration were at the same time focused on meeting the needs of the indigenous population of the North and on the harmonious matching of these needs with the interests of the centralized power. It was the consistency of interests and needs of the subject and the object of management that, in his opinion, ensured the effectiveness of the Soviet policy and warranted its consolidated support from the population. Gurvich believed that the modernization of the culture of the indigenous peoples of the North was a reliable means of implementing the equality of all peoples, proclaimed in the country, and believed that achieving this equality was in demand among the indigenous population of the North. The researcher was convinced that the future does not lie in the preservation of traditional aspects of culture, but in the development of ethnic culture in the context of inevitable socio-cultural transformations. Gurvich's research proves the inevitability and necessity of introducing the indigenous people of the North to the cultural achievements of other peoples, which, without detracting from their ethnic identity, contributes to their socio-cultural integration within both individual regions and the entire country.

Keywords: I.S. Gurvich; policy of paternalism; culture of indigenous peoples of the North; ethnic specificity of indigenous culture 